Vol. LXVI 2015

\title{
SELECTION OF CUTTING INSERTS FOR ALUMINUM ALLOYS MACHINING BY USING MCDM METHOD
}

\author{
MADIĆ Miloš \\ Faculty of Mechanical Engineering in Niš / Department for Production, IT and Management, University of Niš, \\ Niš, Serbia,madic@masfak.ni.ac.rs \\ RADOVANOVIĆ Miroslav \\ Faculty of Mechanical Engineering in Niš / Department for Production, IT and Management, University of Niš, \\ Niš, Serbia, mirado@masfak.ni.ac.rs \\ PETKOVIĆ Dušan \\ Faculty of Mechanical Engineering in Niš / Department for Production, IT and Management, University of Niš, \\ Niš, Serbia, dulep@masfak.ni.ac.rs \\ NEDIĆ Bogdan \\ Faculty of Engineering / Department for production engineering, University of Kragujevac, Kragujevac, Serbia, \\ nedic@kg.ac.rs
}

\begin{abstract}
Machining of aluminum and its alloys requires the use of cutting tools with special geometry and material. Since there exists a number of cutting tools for aluminum machining, each with unique characteristics, selection of the most appropriate cutting tool for a given application is very complex task which can be viewed as a multi-criteria decision making (MCDM) problem. This paper is focused on multi-criteria analysis of VCGT cutting inserts for aluminum alloys turning by applying recently developed MCDM method, i.e. weighted aggregated sum product assessment (WASPAS) method. The MCDM model was defined using the available catalogue data from cutting tool manufacturers.
\end{abstract} method

Key words: aluminum alloys, machining, turning, multi-criteria decision making, WASPAS

\section{Introduction}

Aluminum and its alloys represent engineering materials with increasing application. Chemically pure aluminum is brittle and soft low density metallic material. Because the ratio of electrical conductivity and density is the most favorable of all metals, pure aluminum is used to make electric conductors. In order to improve its techno-technological properties, aluminum is alloyed with copper, magnesium, manganese, silicon and zinc. These alloys are widely used in building and construction, transport, chemical, food, packaging, shipbuilding and other industries since they have favorable specific tensile strength (ratio of tensile strength and density).

The usual machining processes can be easily performed when using aluminum workpieces. In general, compared with other metals, aluminum and its alloys have excellent machining properties. When machining aluminum and some of its alloys, the chips are continuous, rather thick, strong and not readily broken [1].

Considering the wide range of alloys available, it is necessary to go into details regarding the machining characteristics of aluminum alloys [2]. The machining of a given aluminum alloy depends on a number of independent and partially dependent parameters such as machine tool parameters, cutting tool material and geometry, cutting parameters (depth of cut, feed rate, cutting speed), cutting fluid, etc. At the same time the overall machining performance is reflected by considering chip-form/chip breakability, tool-wear/tool-life, cutting force/power/torque, surface roughness/surface integrity and part accuracy [3].

This paper focuses on multi-criteria analysis of VCGT cutting inserts for aluminum turning while considering depth of cut, feed rate, cutting speed and cost as criteria for assessment of alternatives performances. An attempt was made to explore the applicability of recently developed MCDM method, i.e. weighted aggregated sum product assessment (WASPAS) for ranking of six cutting inserts. Firstly, 
using the available catalogue data from five cutting tool manufacturers, a MCDM model was defined. In the study equal importance of criteria was assumed, however, stability of obtained complete rankings of alternatives was performed by varying the values of coefficient of linear combination.

\section{Aluminum alloys machinability}

Aluminum alloys have in general high rates of machinability table by most of the criteria. Tool wear, surface roughness and form of the chip can be considered as one of the most important criteria [13].

The tool wear while machining aluminum alloys occurs due to abrasion of the free surface. Consequently, the deciding criterion for measuring tool life objectively is the wear width VB [2]. Tool wear problems arise in the case of only a few aluminum alloys [1]. In order to obtain high quality machined surfaces it is preferable to use high cutting speeds since at low cutting speeds a build-up edge is formed. In machining of aluminum alloys two basic chip forms are generated: broken chips and stripped chips. The form of the chips generated during aluminum alloys machining depends on the machining conditions, geometry and materials of the cutting tool, chip breakers, tool wear, etc. The general aim is to obtain short cylindrical or spirally cylindrical chips.

The other general machining conditions recommendations regarding machining of aluminum alloys are as follows [1, 2, 4]. Since aluminium alloys have lower modulus in comparison to other metals, higher feed rates are not recommended and should be determined considering required surface finish. This also stands for the depth of cut. Very important aspect in aluminum alloys machining is lubrication. Lubrication agent is used to remove the heat generated in the cutting zone, reduce friction between the cutting tool and workpiece and assist in the chips removal. Although different types of lubrication agents are available, oil emulsions are usually recommended.

Aluminum and its alloys can be efficiently machined only if the suitable rake angle is selected, if the machining is performed with higher cutting speeds and if appropriate lubrication agent is used for a given machining conditions.

\section{Cutting tools for aluminum alloys}

In this study, the focus is on multi-criteria analysis of VCGT (ISO designation) cutting inserts for aluminum alloys turning. Depth of cut, feed rate, cutting speed are maximization criteria where higher assessment values alternatives are preferred, whereas cost is the minimization criterion where smaller assessment values alternatives are preferred.

The VCGT cutting inserts of five cutting tool manufacturers such as Sandvik, Carboloy, Tungaloy, Plansee Tizit and Widia were considered in the analysis. Based on the available data from manufacturers catalogues, the decision matrix representing nominal values was constructed (Table 1).

Table 1: Multi-criteria analysis of different VCGT inserts (decision matrix)

\begin{tabular}{|c|c|c|c|c|}
\hline $\begin{array}{c}\text { Cutting } \\
\text { insert }\end{array}$ & $\begin{array}{c}\text { Depth of cut } \\
(\mathbf{m m})\end{array}$ & $\begin{array}{c}\text { Feed rate } \\
\mathbf{( m m} / \mathbf{r e v})\end{array}$ & $\begin{array}{c}\text { Cutting speed } \\
\text { (m/min) }\end{array}$ & Cost (EUR) \\
\hline $\mathbf{1}$ & 1.5 & 0.4 & 2000 & 4.6 \\
\hline $\mathbf{2}$ & 2.5 & 0.3 & 400 & 3.5 \\
\hline $\mathbf{3}$ & 2 & 0.3 & 600 & 3.3 \\
\hline $\mathbf{4}$ & 3 & 0.2 & 1500 & 4.3 \\
\hline $\mathbf{5}$ & 2.5 & 0.25 & 1000 & 4 \\
\hline
\end{tabular}

\section{WASPAS method}

In this paper, the WASPAS method was applied in order to select the most suitable VCGT cutting insert for aluminum turning.

The WASPAS method for solving MCDM problems was proposed by Zavadskas et al. [5]. In essence this method represents a unique combination of two well known MCDM methods, i.e. weighted sum method (WSM) and weighted product method (WPM). The main procedure of the method for solving MCDM problems includes several steps. The algorithmic procedure of the WASPAS method is given in Figure 1, where $x_{i j}$ is the assessment value of the $i$-th alternative with respect to the $j$-th criterion; $\bar{x}_{i j}$ is normalized value of $x_{i j}$; $w_{j}$ is criteria weight which represents relative importance of the $j$-th criterion and $\lambda$ is coefficient of linear combination. 
Figure 1: WASPAS algorithmic procedure

Development of decision matrix

\begin{tabular}{|c|c|}
\hline \multicolumn{2}{|c|}{ Normalization of decision matrix: } \\
\hline for maximization criteria & for minimization criteria \\
\hline $\bar{x}_{i j}=\frac{x_{i j}}{\max _{i} x_{i j}}$ & $\bar{x}_{i j}=\frac{\min _{i} x_{i j}}{x_{i j}}$ \\
\hline
\end{tabular}

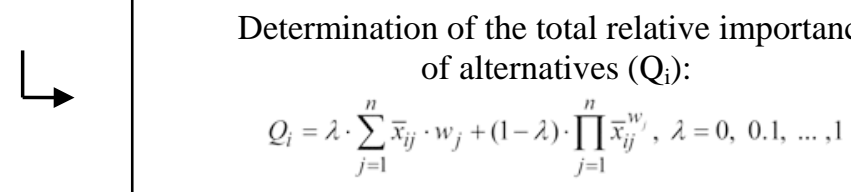

\section{Results and discussion}

One of the main issues while solving MCDM problems is determination of the relative importance of the criteria, i.e. criteria weights. Although there are different subjective and objective methods for determination of criteria weights, in this study equal importance of all criteria is considered. Thus the resulting criteria weight vector is $\mathrm{w}=[0.25,0.25,0.25,0.25]$. The computational details of the WASPAS method when using normalization equations, weight vector and coefficient of linear combination of $\lambda=0.5$ are given in Table 2 .

Table 2: Computational details of the WASPAS method

\begin{tabular}{|c|c|c|c|c|c|c|}
\hline Cutting insert & \multicolumn{4}{|c|}{ Normalized decision matrix } & Total relative importance $\left(Q_{i}\right)$ & Ranking \\
\hline 1 & 0.5 & 1 & 1 & 0.717 & 0.789121 & 1 \\
\hline 2 & 0.833 & 0.75 & 0.2 & 0.943 & 0.633734 & 5 \\
\hline 3 & 0.667 & 0.75 & 0.3 & 1 & 0.65075 & 4 \\
\hline 4 & 1 & 0.5 & 0.75 & 0.767 & 0.743398 & 2 \\
\hline 5 & 0.833 & 0.625 & 0.5 & 0.825 & 0.688325 & 3 \\
\hline
\end{tabular}

Consideration of different scenarios, beneficial for investigation of the stability of obtained rankings of alternatives, was performed by varying the values of coefficient of linear combination $(\lambda)$ while retaining same criteria weights. Figure 2 shows the effect of varying values of $\lambda$ on total relative importance values and rankings of the considered cutting inserts.

Figure 2: Variations of alternatives total relative importance (a) and rankings (b) with respect to $\lambda$

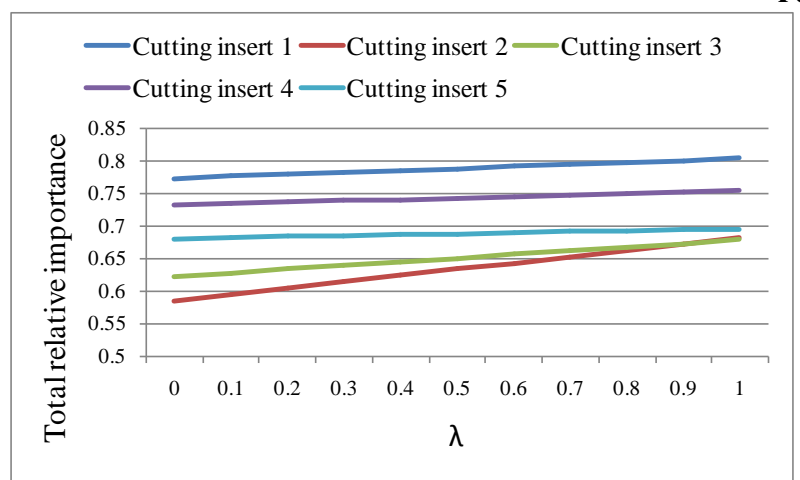

a)

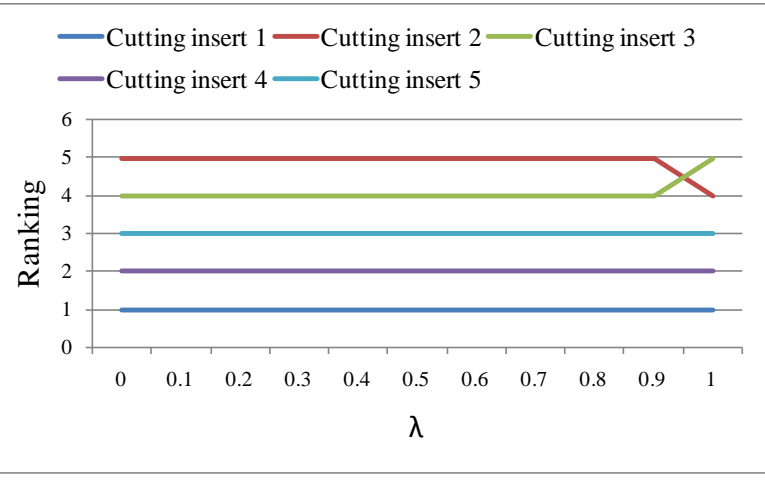

b)

From Figure 2 it can be observed that higher total relative importance values are obtained for the higher values of $\lambda$. Also, it is clear that the rankings of cutting inserts 1, 4 and 5 remain unaffected to the $\lambda$. On the other hand, in the case of cutting inserts 2 and 3 , a rank reversal occurs for $\lambda \geq 0.9$. However, in 
all cases, cutting inserts 2 and 3 are the least preferred having penultimate and the last ranking of all cutting inserts.

Considering small differences in total relative importance values as well as costs, cutting inserts 1 and 4 can be regarded as the best choices, respectively. Cutting insert 3 is recommended choice, if for some reason the price as a criterion gains even greater importance.

\section{Conclusion}

Machining of aluminum and its alloys requires the use of cutting tools with special geometry and material. For economic reasons, cutting tools with inserts (indexable tools) are being increasingly used for aluminum machining.

In this paper multi-criteria analysis of VCGT cutting inserts for aluminum alloys turning based on the application of the WASPAS method was presented. The MCDM model for the selection of VCGT cutting insert for aluminum alloys turning was defined using the available catalogue data from cutting tool manufacturers. The MCDM model, i.e. decision matrix consisted of four criteria such as depth of cut, feed rate, cutting speed and cost, and five different cutting inserts. The obtained results from MCDM analysis suggested that cutting inserts 1 and 4 are the best alternatives, while cutting insert 2 obtained lowest ranking. The effect of coefficient of linear combination on the ranking performance of the WASPAS method was also studied, revealing the fact that there exists strong resistance against rank reversal of the considered cutting inserts.

Regarding the computational procedure it was observed that WASPAS method can serve as effective decision support tool for manufacturing engineers. Selection of the best suited cutting insert for aluminum alloys machining is very important task in machining process planning stage. Comprehensive analysis of this complex problem for a given machining application should consider additional criteria such as chip-form/chip breakability, tolerances, surface finish, part accuracy, process capabilities, productivity, tool wear, etc. and this will be scope of future research. Future work will also focus on selection of cutting inserts for aluminum alloys machining considering interval data of assessment values alternatives with respect to the criteria.

\section{Acknowledgments}

The paper is a part of the research done within the project TR35034. The authors would like to thank to the Ministry of Education and Science, Republic of Serbia.

\section{References}

- E. Trent, P. Wright, Metal cutting, Butterworth Heinemann, (2000).

- P. Johne, Machining of products, Aluminum Verlag, Düsseldorf, (1994).

- S. Jawahir, A.K. Balaji, Machining, pp. 1063-1103. In: Handbook of Aluminum, physical metallurgy and processes, Marcel Dekker, (2003).

- http://www.espimetals.com

- E.K. Zavadskas, Z. Turskis, J. Antucheviciene, A. Zakarevicius, Optimization of weighted aggregated sum product assessment, Electronics and Electrical Engineering, Vol. 122, pp. 3-6, (2012). 